FONSECA, TÂNIA DE F. G.; RODRIGUES, ISADORA, F.; BORGES, SANNY C. G. Manhã de leitura afetuosa: um programa biblioterápico 74 com crianças com perfil do transtorno do déficit de atenção e hiperatividade (TDAH) em escola municipal de Formiga-MG

\title{
MANHÃ DE LEITURA AFETUOSA: UM PROGRAMA BIBLIOTERÁPICO COM CRIANÇAS COM O PERFIL DO TRANSTORNO DO DÉFICIT DE ATENÇÃO E HIPERATIVIDADE (TDAH) EM ESCOLA MUNICIPAL DE FORMIGA- MG
}

\author{
Tânia de Fátima Gontijo Fonseca \\ Especialista em Administração de Sistemas de Informação. \\ Docente do Curso de Biblioteconomia/UNIFOR \\ Isadora Ferreira Rodrigues \\ Graduada em Biblioteconomia pelo UNIFOR \\ Sanny Catteriny Gregório Borges \\ Graduada em Biblioteconomia pelo UNIFOR
}

Recebido em: 07/03/2012

Aprovado em: 22/10/2012

\begin{abstract}
RESUMO
Relato de caso sobre o incentivo à leitura com crianças com características do Transtorno de Déficit de Atenção e Hiperatividade (TDAH) em uma escola de Formiga - MG. Apresenta um programa biblioterápico desenvolvido por meio da contação de histórias e atividades lúdico recreativas. Caracteriza-se como pesquisa-ação utilizando-se a observação participante numa abordagem qualitativa com análise de relatórios e depoimentos. Percebeu-se que o uso de técnicas de biblioterapia, contação de histórias, oficinas de criatividade e atividades lúdicas faz com que o grupo de crianças apresente melhoras no relacionamento social, autoestima e no desempenho escolar. Conclui-se que houve uma melhora significante das crianças havendo progressos na leitura e no processo de aprendizagem. Apresentaram também sentimentos de satisfação e de valorização.
\end{abstract}

Palavras-chave: Biblioterapia. Leitura. Hiperatividade.

\section{MORNING READING AFFECTIONATE: BIBLIOTHERAPIC PROGRAM WITH THE PROFILE OF CHILDREN WITH ATTENTION DEFICIT DISORDER OF AND HYPERACTIVITY DISORDER (ADHD) IN MUNICIPAL SCHOOL OF FORMIGA-MG}

\begin{abstract}
Case report to encourage reading in children with Attention Deficit Disorder and Hyperactivity Disorder (ADHD) in a school of Formiga - MG. Program bibliotherapic developed through storytelling and entertaining recreational activities. The bibliotherapy - therapy through books causes effects on listeners leading to an exchange of information among people and can influence and thrill them according to their realities. The results led to realize that the use of bibliotherapy techniques, storytelling, creativity workshops and recreational activities makes the group of children shows improvements in social relationships, self-esteem and school performance. It is concluded that there were progress in reading and learning process. They also showed feelings of satisfaction and appreciation.
\end{abstract}


FONSECA, TÂNIA DE F. G.; RODRIGUES, ISADORA, F.; BORGES, SANNY C. G. Manhã de leitura afetuosa: um programa biblioterápico 75 com crianças com perfil do transtorno do déficit de atenção e hiperatividade (TDAH) em escola municipal de Formiga-MG

Keywords: Bibliotherapy. Reading. Hyperactivity.

\section{INTRODUÇÃO}

O Transtorno de Déficit de Atenção e Hiperatividade (TDAH) está presente com frequência no ambiente escolar. Por se tratar de um assunto frágil e delicado, merece uma atenção especial visto que é identificado na idade escolar.

Partindo dessa premissa, surgiu o interesse em saber que tipo de trabalho pode-se desenvolver para apoiar e melhorar os aspectos motivacionais, sociais e educacionais, juntamente com a autoestima das crianças com características do TDAH.

Neste contexto, acreditou-se que um programa biblioterápico em ambiente fora da escola poderia ser uma excelente estratégia para socializar, motivar, elevar a autoestima e até mesmo iniciar um processo de leitura nestas crianças. Mattos (2007, p. 83) revela que: o modo de reduzir as dificuldades de relacionamento é por meio de um treino de habilidades sociais.

Lima e Gonçalves (2006, p. 126) confirmam que:

[...] crianças com esse perfil: precisam que o material seja apresentado de forma a "capturar" sua atenção. Quanto mais cativante/ interessante for o material, mas provável que o estudante preste atenção e permaneça na tarefa (podem ser usados tipos variados de materiais visuais, com cores, desenhos, gravuras).

Considera-se um estudo relevante por apresentar três razões: um problema real nas escolas de qualquer município, a falta de literatura no contexto que envolve o efeito da biblioterapia em um possível portador de TDAH e a comprovação de que com um trabalho diferenciado com histórias é possível trabalhar a afetividade, reduzir dificuldades de relacionamento, de concentração e motivar a criança para a leitura.

Esta pesquisa tem como finalidade mostrar que um programa biblioterápico é pertinente ao bom desempenho escolar para crianças que apresentam sintomas do Transtorno de Déficit de Atenção e Hiperatividade.

\section{TRANSTORNO DE DEFICIT DE ATENÇÃO E HIPERATIVIDADE: DEFINIÇÕES E CARACTERÍSTICAS}

Segundo a literatura, o transtorno de déficit de atenção e hiperatividade (TDAH) implica em uma desordem de comportamentos diferenciados da vida social, emocional, escolar e familiar do portador. (STEFANI; MASTRONIANNI; VIOTTO FILHO, 2009). 
FONSECA, TÂNIA DE F. G.; RODRIGUES, ISADORA, F.; BORGES, SANNY C. G. Manhã de leitura afetuosa: um programa biblioterápico 76 com crianças com perfil do transtorno do déficit de atenção e hiperatividade (TDAH) em escola municipal de Formiga-MG

Os portadores deste transtorno são pessoas que não seguem um padrão, são pessoas com históricos pessoais, personalidades diferentes, possuem um estilo de vida particular.

O transtorno de déficit de atenção, segundo Rizo e Rangé (2003, p. 2), possui como sintomas principais:

[...] dificuldade de prestar atenção a detalhes ou errar por descuido em atividades escolares e de trabalho; dificuldade para manter a atenção em tarefas e atividades lúdicas; parece não escutar quando lhe dirigem a palavra; não seguir instruções e não terminar tarefas escolares, domésticas ou deveres profissionais; dificuldade em organizar tarefas e atividades; evitar ou relutar em envolver-se em tarefas que exijam esforço mental constante (como tarefas escolares ou deveres de casa); perder coisas necessárias para realização de atividades (p.e.:brinquedos, tarefas escolares, lápis, livros ou outros materiais); ser distraído por estímulos alheios à tarefa e apresentar esquecimentos em atividades diárias. (RIZO; RANGÉ, 2003).

Ainda segundo os autores anteriormente citados, a hiperatividade pode ser reconhecida através dos seguintes sintomas:

agitar mãos e pés ou se remexer na cadeira; abandonar sua cadeira em sa-la de aula ou outras situações nas quais se espera que permaneça sentado; correr ou escalar em demasia, em situações nas quais isto é inapropriado; dificuldade em brincar ou envolver-se silenciosamente em atividades de lazer; estar frequentemente "à mil" ou muitas vezes agir como se estivesse "a todo vapor"; falar em demasia.

Além desses sintomas, Mattos (2007, p. 17) ainda ressalta sintomas que não estão listados nos critérios tradicionais para se fazer o diagnóstico, mas são muito comuns:

a) baixa auto estima (sic);

b) adiamento crônico das coisas;

c) mudança de interesse o tempo todo;

d) intolerância e evitação de situações monótonas ou repetitivas;

e) busca frequente por coisas estimulantes ou simplesmente diferentes;

f) variações frequentes de humor;

g) dificuldades de planejar e manter-se no plano ao longo do tempo;

d) dificuldade para ativar-se sozinho para fazer as coisas (principalmente as rotineiras ou "chatas").

O sinal que pode diferenciar uma criança com TDAH de outra que não seja é a intensidade, a frequência e a constância da desatenção, hiperatividade e impulsividade. Com a criança portadora deste transtorno, tudo parece estar "a mais".

Geralmente estas crianças sofrem uma espécie de preconceito por parte dos colegas de sala e até mesmo dos próprios professores que desconhecem o caso. Confundem o comportamento da criança como má educação, preguiça, rebeldia e irresponsabilidade.

Diante de todo este contexto, o profissional bibliotecário, com todo seu conhecimento, deve atuar juntamente com o professor, auxiliando por meio de aplicação de um programa biblioterápico 
que consiste em trabalhar com as crianças utilizando a leitura terapêutica, ou seja, a biblioterapia, como também promover reflexões que possam mudar comportamentos e atitudes.

\section{UTILIZAÇÃO DE UM PROGRAMA BIBLIOTERÁPICO EM FUNÇÃO DA MELHORIA DA AUTOESTIMA}

\subsection{Biblioterapia}

De acordo com Caldin (2001 p. 2), "a biblioterapia é originada de dois termos gregos biblion - livro, therapeia - tratamento".

Percebeu-se que a biblioterapia poderia ser usada não só em tratamentos hospitalares, mas em várias outras situações, educação, reabilitação, problemas pessoais e faixas etárias diferentes. Com base neste contexto, Campos, Pereira e Marcinko apud Guedes e Ferreira deixam claro que a biblioterapia pode ser subdividida em:

a) Biblioterapia Institucional: é caracterizada pelo uso de textos de higiene mental, geralmente usado para pessoas hospitalizadas. Busca auxiliar um grupo ou uma instituição, prestar informação ao usuário e esclarecê-lo sobre um problema especifico, ajudar na tomada de decisões e reorientação de seu comportamento conforme o objetivo definido para o trabalho. É utilizada uma literatura didática. Essa terapia pode ser usada em grupo ou individual, aplicada por médicos ou bibliotecários.

b) Biblioterapia Clinica: busca trabalhar o comportamento das pessoas em seu desenvolvimento como questões emocionais. Sua atividade é feita em hospitais, clinicas e organizações de saúde mental. Seu objetivo é fazer com que os pacientes modifiquem suas atitudes, e comportamento, encontrando soluções ou melhoras em sua atitude quanto ao seu problema. Neste caso é utilizado a literatura imaginativa, pode ser realizada por bibliotecários, psicoterapeutas, e médicos.

c) Biblioterapia Desenvolvimental: Tem a finalidade de ajudar as pessoas em tarefas comuns alem de auxiliar a lidar com problemas pessoais do cotidiano, para o desenvolvimento pessoal, tem um caráter preventivo e corretivo, utilizado muito em instituições educacionais. É empregada a literatura didática e imaginativa. Como não é ligada a medicina é realizada por bibliotecários, educadores, e outros.

É importante salientar que o método biblioterapêutico consiste na linguagem, ou seja, as palavras causam efeitos nos ouvintes; conduzindo uma troca de informações entre as pessoas que poderá influenciá-la, emocioná-la, passar afeto, angústia, alegria, dor, pavor e entusiasmo.

Para entender melhor o processo biblioterapêutico, como age nas pessoas, torna-se necessário conhecer seus componentes que são: catarse, humor, identificação, introjeção, projeção e a introspecção. De acordo com Nunes e Franco ( 2007, p. 8) :

a) catarse (pacificação, serenidade e alívio das emoções) - a leitura de textos literários exerce o poder de purificação psicológica e intelectual; 
FONSECA, TÂNIA DE F. G.; RODRIGUES, ISADORA, F.; BORGES, SANNY C. G. Manhã de leitura afetuosa: um programa biblioterápico 78 com crianças com perfil do transtorno do déficit de atenção e hiperatividade (TDAH) em escola municipal de Formiga-MG

b) humor (ação do super ego sobre o ego a fim de protegê-lo contra a dor) - o humor é a rebelião do ego contra as circunstancias adversas transformando o que poderia ser objeto de dor em objeto de prazer;

c) identificação, processo psicológico pelo qual um sujeito assimila um aspecto, uma propriedade, um atributo de outro e se transforma, total ou parcialmente, seguindo o modelo desse outro;

d) Introjeção, estritamente ligada à identificação, consiste na absorção do sujeito de fora para dentro;

e) projeção- transferência aos outros de nossas ideias, sentimentos, intenções, expectativas e desejos. É a operação pela qual o sujeito expulsa de si e localiza no outro -pessoa ou coisa - qualidades, sentimentos, desejos e mesmo 'objetos' que lê, desconhece, ou recusa nele.;

f) introspecção observação de uma pessoa de seus próprios processos mentais, o individuo é levado a refletir sobre os seus sentimentos.

Sendo assim, um programa biblioterápico influencia de forma direta na vida das crianças, podendo ser aplicado por meio da contação de histórias, atividades lúdicas e oficinas. Contar história é uma arte... é tão linda! É ela que equilibra o que é ouvido como que é sentido [...], afirma Abramovich (1989) apud Barcellos e Neves (1995, p. 16).

\subsection{Contação de histórias}

A contação de histórias, uma vez aplicada, faz com que as crianças se assemelhem com o personagem da história, trazendo esta experiência para junto de seu convívio social e escolar.

Durante a execução do Projeto "Manhã de Leitura Afetuosa" no Centro Universitário de Formiga-UNIFOR, recorreu-se a várias técnicas de contação de história, como por exemplo: teatro, fantoches, histórias em vídeos, lavadeiras contadoras de histórias e dobraduras, datashow, dentre outras.

Dentre as muitas histórias trabalhadas, listam-se abaixo duas consideradas marcantes durante a execução do projeto:

\section{História "Xico, Bicho Carpinteiro"}

a) tema biblioterápico: hiperatividade com a possibilidade de aguçar a criatividade;

b) técnica utilizada: Baú de história;

c) oficina de Criatividade: Mosaico do personagem;

d) atividade recreativa: oficina de dança.

\section{História "Lilito, um amor de caracol"}

a) tema biblioterápico: dificuldade de aprendizagem e a necessidade de superação de quem as possui;

b) técnica utilizada: datashow; 
FONSECA, TÂNIA DE F. G.; RODRIGUES, ISADORA, F.; BORGES, SANNY C. G. Manhã de leitura afetuosa: um programa biblioterápico 79 com crianças com perfil do transtorno do déficit de atenção e hiperatividade (TDAH) em escola municipal de Formiga-MG

c) oficina de criatividade: porta recado em madeira com a personagem;

d) atividade recreativa: encontro com o reitor do UNIFOR.

Baseado no programa biblioterápico exemplificado acima, acreditou-se que a arte favorece o desenvolvimento e a superação de limitações pessoais e a melhor habilidade em lidar com os seus próprios conflitos. Neste caso, o objetivo seria buscar na arte o resgate da autoimagem de alunos com dificuldades de leitura e escrita. Segundo a UNESCO (2005, p. 19), [...] através da arte a humanidade expressa, sem restrições, sentimentos e emoções.

Deste modo, é importante salientar que a reescrita do conto e leitura por meio da arte dá significado para o aluno, através de desenho, música, pintura etc. O profissional deve estar atento, "saber olhar para saber escutar" para observar o comportamento da criança frente a cada passo resgatando sua autoimagem e, de fato, favorecendo o aprendizado.

\subsection{Atividades lúdico-recreativas}

As autoras acreditam que a realização e o desenvolvimento de atividades lúdico-recreativas fazem com que o "ego" infantil seja motivado. A criança sente prazer em realizar suas atividades e até mesmo obrigações em seu ambiente escolar e consequentemente na sua vida pessoal.

Com esta linha de pensamento, desenvolveram-se as seguintes atividades lúdico recreativas:

a) equoterapia: $\mathrm{O}$ passeio no campus, atividade realizada em parceira com o Curso de Veterinária que disponibilizou o cavalo e estagiários para o monitoramento da atividade.

[...] a equoterapia é destinada não apenas às pessoas especiais, mas também no apoio às dificuldades escolares, casos de dependência física, stress, bem como a todos que procuram novas oportunidades de crescimento, melhoria na qualidade de vida e ainda um melhor equilíbrio tanto físico como mental. (MEDEIROS; DIAS, 2003).

b) dinâmicas e brincadeiras: utilizadas como auxílio para a avaliação de características pessoais.

Araújo (1992, p. 21) complementa quando nos diz que o brincar [...] é um instrumento incentivador e motivador no processo de aprendizagem, já que este dá à criança uma razão própria que faz exercer de maneira significativa sua inteligência e sua necessidade de investigação.

Abaixo seguem alguns exemplos de atividades que ocorreram durante a execução do projeto:

a) dinâmica do bombom - foram trabalhadas as qualidades de cada criança envolvida;

b) circuito de atividades no campus do UNIFOR - destacou-se o trabalho em equipe e a socialização;

c) utilização de oficinas de criatividade - despertou nas crianças o gosto pela arte; 
FONSECA, TÂNIA DE F. G.; RODRIGUES, ISADORA, F.; BORGES, SANNY C. G. Manhã de leitura afetuosa: um programa biblioterápico 80 com crianças com perfil do transtorno do déficit de atenção e hiperatividade (TDAH) em escola municipal de Formiga-MG

d) visitas às dependências do UNIFOR;

e) entrevista com o Reitor - momento descontraído em que as crianças puderam satisfazer sua curiosidade em conhecer o suposto “dono” do Centro Universitário.

\subsection{Arte: oficina de criatividade}

"Por meio da Arte é possível desenvolver a capacidade crítica permitindo ao indivíduo analisar a realidade percebida e desenvolver a criatividade de maneira a mudar a realidade analisada.” (BARBOSA, 2003, p. 18 apud MELO et al, 2009, p. 607).

Realizaram-se atividades que envolviam a arte como, por exemplo, a decoupagem em pratos, em MDF e a pintura em tela.

Decoupagem consiste num sistema de colagem de recorte de papel ou até mesmo panos, em objetivos diferenciados; a pintura em tela proporciona à criança um espaço livre para usar sua criatividade na mistura das cores, além de estimular a coordenação motora.

Uma vez assim, Melo et al ( 2009, p. 607) relatam:

[...] expressões como o recorte, a colagem, a construção, a impressão, o desenho e a pintura são fundamentais para o desenvolvimento físico e mental da criança. O desenho pode ser na areia, no papel, na terra, no cimento, na parede; com dedo, com vara, muitas oportunidades devem ser exploradas.

Com base neste contexto, as crianças demonstram uma espontaneidade muito grande; através disso pode-se criar possibilidades em que a estimulação ocorre por meio de atividades diferenciadas.

\section{MATERIAIS E MÉTODOS}

Esta pesquisa é definida como pesquisa exploratória, a qual segundo Gil (2009 p. 41)

[...] caracteriza por uma pesquisa onde se encontra maior familiaridade com o problema; e pesquisas descritivas, que têm como objetivo a descrição das características de determinada população ou fenômeno, que por sua vez, utiliza-se técnicas padronizadas de coleta de dados, questionários e a observação.

Em relação ao delineamento, este estudo se classifica como pesquisa-ação, que Lima (2008, p. 37) define como: 
Método que tem por característica principal particular, simultaneamente, o exercício da pesquisa à ação participante sobre a realidade, objeto da investigação. Parte do pressuposto de que o(s) pesquisador(es) e os atores envolvidos no processo investigatório são agentes complementares na medida em que são co-responsáveis ( sic) pelas etapas que caracterizam a concepção do projeto de pesquisa, sua execução e elaboração dos resultados alcançados, tanto em termos de produção quanto de aplicação do conhecimento.

Com base numa metodologia crítica e reflexiva, foi utilizada, para a elaboração deste relato de experiências, a técnica de observação participante artificial, uma vez que, [...] o observador se integra ao grupo com finalidade de obter informações. (MARCOKI; LAKATOS, 2010, p. 79).

Paralela à observação, optou-se por uma abordagem qualitativa que, conforme Minayo (1994, p. 212):

A pesquisa qualitativa responde a questões muito particulares [...] ela trabalha com o universo de significados, motivos, aspirações. Crenças, valores e atitudes, o que corresponde a um espaço mais profundo das relações, dos processos e dos fenômenos que não podem ser reduzidos a operacionalização de variáveis.

Esta pesquisa envolveu 14 crianças da Escola Municipal José Honorato de Castro, situada na cidade de Formiga-MG, na Vila José Branco, visto que esse bairro possui altos índices de criminalidade, marginalidade, envolvimento com entorpecentes e também famílias desestruturadas.

O grupo estudado foi composto de 6 meninas e 8 meninos de baixo desempenho escolar e algumas características de hiperatividade, matriculadas regularmente no $3^{\circ}, 4^{\circ}$ e $5^{\circ}$ ano do ensino fundamental, com a faixa etária de 8 a 12 anos.

As crianças foram escolhidas intencionalmente pelos professores, pedagogos e pela diretora por apresentarem características que as prejudicam no seu ambiente escolar e social. Esta equipe emitiu um pequeno relato sobre o perfil de cada criança.

As pesquisadoras elaboraram um relatório a cada visita, a fim de apresentarem as conclusões que poderiam ser inferidas nos resultados e discussões. Os professores das crianças atendidas emitiram um relatório final, enunciando o desenvolvimento e mudança de comportamento, em sala de aula, dos alunos (pesquisados) durante o ano letivo.

Recorreu-se também à coleta de depoimentos dos respectivos professores e dos alunos envolvidos na pesquisa.

\section{RESULTADOS E DISCUSSÕES}

Uma vez selecionada a escola para o desenvolvimento deste projeto, procurou-se uma maneira correta para que estas crianças participassem do projeto como "convidadas", para não haver possíveis rotulações negativas entre os colegas. 
Diante disto, a equipe pedagógica, com as crianças já selecionadas, simulou um "sorteio intencionado" durante a abertura do projeto Manhã de Leitura Afetuosa na respectiva escola, onde cada criança recebeu um convite VIP para participar dos encontros que decorreriam durante o ano. Neste evento, procurou-se instigar estas crianças a criarem expectativas, deixando-as sedentas de curiosidade e vontade de iniciar as atividades.

De acordo com relatório enviado, tratava-se de crianças com o seguinte perfil apresentado no (GRAF. 1) abaixo:

Gráfico 1 - Perfil das crianças ao iniciarem o projeto

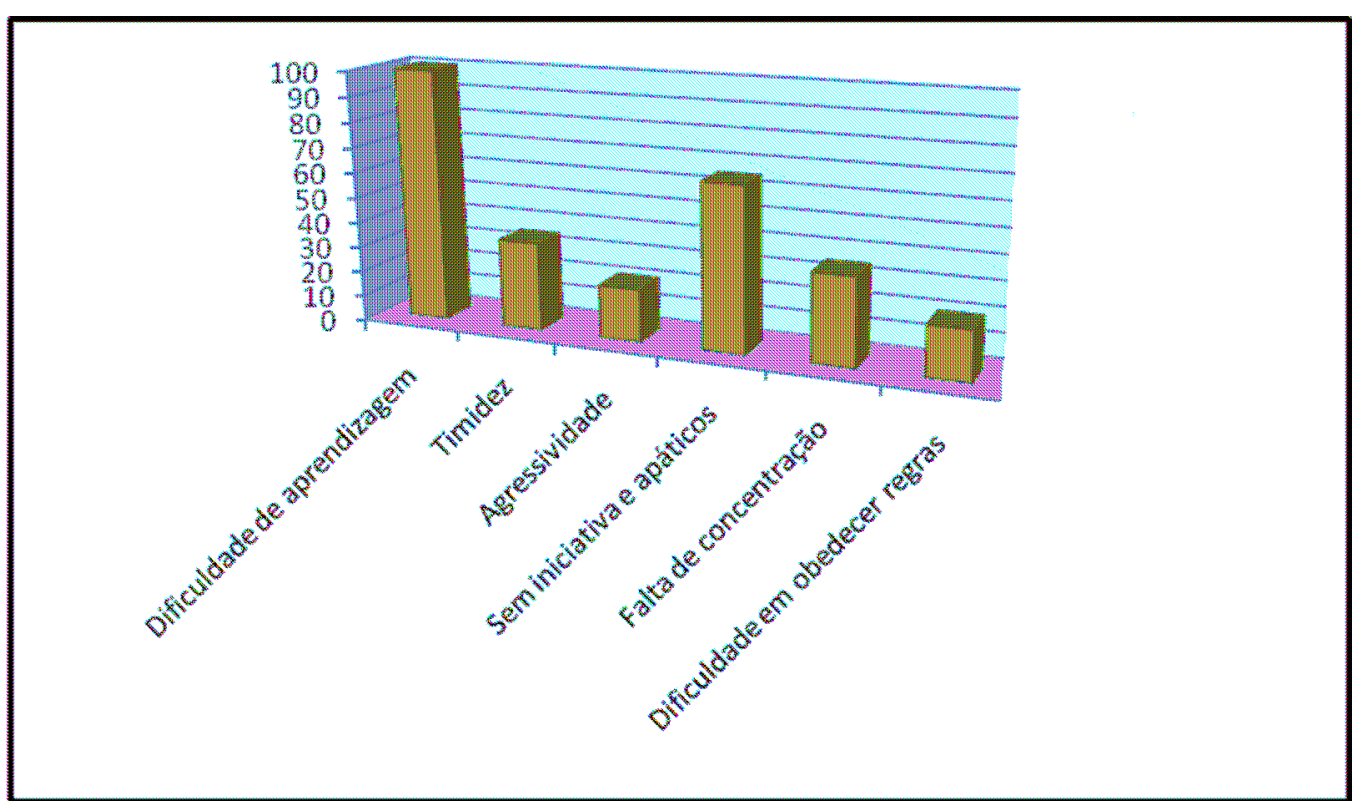

Fonte: Relatório do perfil dos alunos que participaram do Projeto enviado pela Escola.

Portanto, como se pode notar, as crianças demonstravam algumas características do Transtorno de Déficit de Atenção e Hiperatividade (TDAH), conforme a literatura define e caracteriza, que implica em uma desordem de comportamentos.

Pôde-se verificar claramente que, já na primeira visita das crianças, havia um grande tumulto. As crianças chegaram empurrando uns aos outros, a todo o momento ridicularizavam o (a) colega. Trocavam palavras duras entre eles, chegando mesmo a não ouvirem as instruções passadas pela equipe.

A partir daí, iniciaram-se os trabalhos informando-lhes sobre quais seriam as regras e o comportamento esperado durante os encontros.

Para melhor envolvimento e interação com as crianças, utilizou-se a negociação para obter um melhor resultado. Era o comportamento versus novidades a cada visita das crianças. 
FONSECA, TÂNIA DE F. G.; RODRIGUES, ISADORA, F.; BORGES, SANNY C. G. Manhã de leitura afetuosa: um programa biblioterápico 83 com crianças com perfil do transtorno do déficit de atenção e hiperatividade (TDAH) em escola municipal de Formiga-MG

A convivência com crianças com o suposto perfil do TDAH exige [...] normas sobre comportamento que precisam ser claramente estabelecidas. Ou seja, [...] que tenha rotinas, que seja previsível e que ele saiba exatamente o que se espera dele. (MATTOS, 2007, p. 70).

Os elogios sempre ajudam a promover a autoestima, enquanto as criticas e os castigos geram frustração e sentimento de inadequação. Inúmeras pesquisas mostram que quando se começa a elogiar determinado comportamento adequado nas pessoas, mesmo sem criticar um outro comportamento inadequado simultâneo, ele tende a aumentar com o passar do tempo e o inadequado tende a diminuir. (MATTOS, 2007, p. 77).

Uma vez elogiada, a criança sentia que possuía capacidade plena de realizar as tarefas a ela determinadas.

A primeira história contada, "Xico, Bicho Carpinteiro", relata a história de um menino hiperativo que destruía seus brinquedos até que um dia percebeu que poderia criar novos brinquedos com o que havia destruído.

Falkenbach e Pires $(2008$, p. 5), com embasamento neste contexto, afirmam que [...] a criança com o Transtorno de Déficit de Atenção e Hiperatividade tem plena capacidade de desenvolver seu potencial criativo.

A maioria das crianças conseguiu assimilar a mensagem da história, respondendo os questionamentos e relacionando o comportamento da personagem com sua realidade.

A história "O cavalinho e a borboleta" permitiu transmitir às crianças o respeito com o próximo. As crianças demonstraram um grande interesse pela técnica utilizada que as fez fixar a atenção sem problemas de disciplinas e qualquer outro tipo de interrupções que viessem desfocar a mensagem da história. Mostraram-se entusiasmadas em confeccionar as máscaras do cavalinho com a borboleta.

"O pássaro da alma", terceira história contada, foi apresentada através do datashow. A história faz uma relação dos sentimentos do ser humano. Observou-se durante os questionamentos que um menino, em particular, sobressaiu conseguindo superar as expectativas da equipe organizadora. Respondeu com profundidade, surpreendendo a todos.

Foi com "Um amor de Caracol”, a quarta história, que as crianças mais se identificaram, uma vez que aborda a luta de um caracol para acompanhar seus amigos na sala de aula. Percebeu-se grande motivação em especial do grupo feminino.

Com a história "As Aventuras de Joana Porcalhona, trabalhou-se a importância da higiene pessoal. Abordou a respeito das influências das amizades. A técnica do teatro utilizada favoreceu a participação direta, com intensa interação por meio de risos e gargalhadas a cada cena decorrida. Houve um entrosamento até dos mais tímidos com as personagens e com os colegas. 
FONSECA, TÂNIA DE F. G.; RODRIGUES, ISADORA, F.; BORGES, SANNY C. G. Manhã de leitura afetuosa: um programa biblioterápico 84 com crianças com perfil do transtorno do déficit de atenção e hiperatividade (TDAH) em escola municipal de Formiga-MG

Assim, oito histórias foram contadas e inúmeros foram os progressos observados. Mudanças de comportamento ocorreram entre os participantes. Mostravam-se mais amáveis uns com os outros e também companheiros nas atividades que eram trabalhadas em equipe.

Durante o percurso, as crianças com timidez excessiva foram se desinibindo, interagindo com os companheiros e com a equipe de estagiárias, demonstrando o gosto e a vontade em desenvolver e participar das atividades propostas. Tornaram-se amorosas e melhoraram incrivelmente a socialização e a autoestima.

É preciso ensinar à criança que ela pode fazer algumas atividades bem e que pode ter problemas com outras atividades. Que se espera que faça o melhor que puder. E para criar nela bons sentimentos, é importante elogiá-la e incentivá-la quando procura fazer alguma coisa, fazendo-a perceber que tem direito de sentir que é importante, que "pode aprender", que "consegue". Levar o educando a querer aprender é um desafio...

Assim, ao término do trabalho, realizou-se uma exposição das produções das crianças no UNIFOR e na escola, durante o encerramento oficial das atividades.

Durante a exposição no UNIFOR, as crianças puderam receber elogios de todos, ficaram encantadas com os trabalhos reunidos, sentiram-se valorizadas e orgulhosas do que foram capazes de produzir.

Logo no início do projeto, às crianças foi proposto um desafio: “esforçar-se para melhorar na escola, no comportamento com os colegas, no respeito com os mais velhos", seria premiado com um troféu aquele que mais se esforçasse em mudar, em ler e aprender. O aluno ganhador do troféu do mais esforçado foi aquele mais tímido que conseguiu ao final do projeto interagir com os colegas de projeto, com os colegas de classe, com a equipe de estagiárias e ainda venceu sua dificuldade de leitura, já no $5^{\circ}$ ano, pois, de acordo com relato da professora e supervisora, além de aprender a ler, chegou mesmo a solicitar à professora para ler em voz alta para sua turma.

Aqui, vale salientar que durante o evento de premiação, todas as crianças foram premiadas, ressaltadas, elogiadas e receberam medalhas por qualidades apresentadas durante 0 desenvolvimento do projeto.

Um fato interessante percebido durante a entrega do troféu foi o apoio e entusiasmo dos colegas de classe em aplaudir o aluno em questão. O que só comprovou que a classe percebeu grandes mudanças nesta criança, além de seu esforço em superar seus limites.

Abaixo, apresentam-se as mudanças de melhora em alguns aspectos avaliados: 


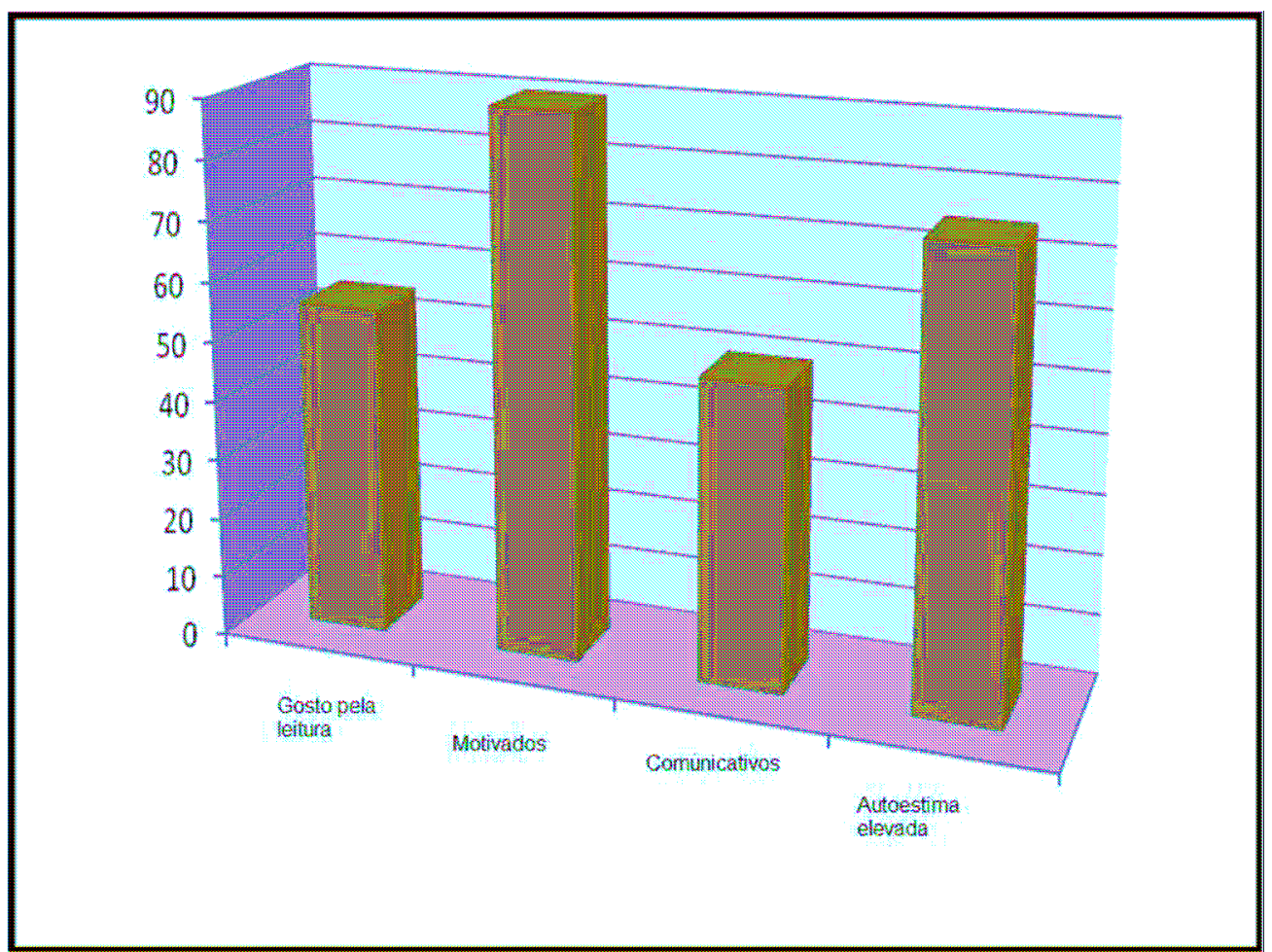

Fonte: Relatório elaborado pela equipe pedagógica, juntamente com a observação realizada durante os encontros, 2011.

Percebe-se que a inclusão escolar é muito importante, mas em casos como este apresentado, não basta apenas colocar crianças com dificuldades de aprendizagem em classes regulares. É preciso, sobretudo, capacitar professores para trabalharem de forma adequada com estas crianças, talvez em salas com menor número de alunos.

Assim sendo, Almeida (2011, p. 6) destaca [...] a importância da seleção certa dos materiais utilizados e de estar atento para a necessidade de constituir equipes multidisciplinares, cujos saberes e fazeres sejam dirigidos ao processo [...].

Aos bibliotecários cabe a responsabilidade de serem as molas propulsoras no que diz respeito ao incentivo à leitura, pois de acordo com Magnani (2001 apud DUARTE; ANDRE, 2008, p. 9): [...] o fracasso escolar de um individuo, em muitos casos, é tido como consequência da falta de estímulo ao habito de leitura, o que vem reforçar a importância do bibliotecário no trabalho de estimular, motivar e elevar a autoestima destas crianças por meio da biblioterapia inserida na maior riqueza existente dentro das bibliotecas, as histórias, ou seja, o mundo fantástico da imaginação.

\section{CONCLUSÃO}


FONSECA, TÂNIA DE F. G.; RODRIGUES, ISADORA, F.; BORGES, SANNY C. G. Manhã de leitura afetuosa: um programa biblioterápico 86 com crianças com perfil do transtorno do déficit de atenção e hiperatividade (TDAH) em escola municipal de Formiga-MG

O transtorno de déficit de atenção e hiperatividade trata-se de um transtorno que leva os portadores a um comportamento diferenciado em sua vida social, emocional, escolar e familiar.

Diante disto, o problema inicial deste projeto foi verificar que tipo de trabalho pode-se desenvolver para apoiar e melhorar os aspectos motivacionais, sociais e educacionais, juntamente com a autoestima das crianças com características do TDAH. Neste sentido, pode-se dizer que a hipótese foi comprovada, uma vez que o uso de um programa biblioterápico fez com que o grupo de criança apresentasse melhoras no relacionamento social, na autoestima e no desempenho escolar.

Houve maior participação nas atividades em sala de aula, ocorrendo progressos na leitura, desenvolveram o interesse pelo processo de aprendizagem e apresentaram sentimentos de satisfação e de valorização.

Com este estudo, foi possível visualizar um novo campo de atuação do profissional bibliotecário, em que o mesmo poderá ser um grande aliado no sentido de trabalhar a motivação, a autoestima, o interesse pela leitura por meio da biblioterapia, facilitando assim a ação da equipe pedagógica com crianças com baixo rendimento escolar e que necessitam de estratégias diferenciadas que os leva a superar seus limites de aprendizagem.

\section{REFERÊNCIAS}

ABROMOVICH, F. Literatura infantil: gostosuras e bobices. São Paulo: Scipione, 1989.

ALMEIDA, G. M. A leitura como tratamento: diversas aplicações da biblioterapia. In: ENCONTRO REGIONAL DE ESTUDANTES DE BIBLIOTECONOMIA, DOCUMENTAÇÃO, CIÊNCIA DA INFORMAÇAO E GESTAO DA INFORMAÇÃO, 14., 2011, São Luis. Anais... Disponível em: <http://rabci.org/rabci/sites/default/files/A\%20LEITURA \%20COMO\% 20TRATAMENTO \%20 diversas\%20aplica\%C3\%A7\%C3\%B5es\%20da\%20biblioterapia.pdf>. Acesso em: 24 set. 2011.

ARAÚJO, V. C. de. O jogo no contexto da educação psicomotora. São Paulo: Cortez, 1992.

CALDIN, C. F. A leitura como função terapêutica: biblioterapia. Encontros Bibli: revista eletronica de Biblioteconomia e Ciência da Informação, Florianópolis, n. 12, p. 32-44, 2001. Disponível em: <http://www.jornal.ufsc.br/index.php/eb/article/ViewFile/36/5200>. Acesso em: 3 abr. 2011.

DUARTE, L. F.; ANDRÉ, T. C. Literatura infantil na hora do conto: a importância da leitura silenciosa e oral segundo Vigotski. In: SIMPOSIO NACIONAL DE EDUCAÇÃO, 1., 2008, Cascavel. Anais... Disponível em: <http://www.unioeste.br/cursos/cascavel/pedagogia/ eventos/2008/6/Artigo\%2003.pdf>. Acesso em: 24 set. 2011. 
FALKENBACH, A. P.; PIRES, E. A aprendizagem e o brincar de crianças em transtorno de déficit de atenção/hiperatividade. Revista Digital, Buenos Aires, ano 12, n. 118, 2008. Disponível em: $<$ http://www.efdeportes.com/efd118/criancas-com-transtorno-de-deficit-de atencaohiperatividade.htm>. Acesso em: 26 fev. 2011.

GIL, A. C. Como classificar as pesquisas? In: Como elaborar projetos de pesquisa. 4. ed. São Paulo: Atlas, 2002. cap. 4, p. 41-56.

LIMA, M. C. Monografia: a engenharia da produção acadêmica. 2. ed. São Paulo: Saraiva, 2008.

LIMA, R. de C.; GONÇALVES, M. F. C. (Org.). Sujeito, escola, representações. Florianópolis: Insular, 2006.

MARCONI, M. de A.; LAKATOS, E. M. Técnicas de pesquisa. 7. ed. São Paulo: Atlas, 2010.

MATTOS, P. No mundo da lua. 7. ed. São Paulo: Lemos Editorial, 2007.

MEDEIROS, M.; DIAS, E. Distúrbios da aprendizagem: a equoterapia na otimização do ambiente terapêutico. Rio de Janeiro: Revinter, 2003.

MELO, A. K. D. et al. Novos olhares sobre o ensino de arte na escola: a contribuição da disciplina arte/educação para o curso de pedagogia. In: SEMINÁRIO EDUCAÇÃO, COMUNICAÇÃO, INCLUSÃO E INTERCULTURALIDADE, 2., 2009, Sergipe. Anais... Disponível em: $<$ http://edapeciufs.dominiotemporario.com/doc/058_AISHA.pdf>. Acesso em: 24 set. 2011.

MINAYO, M. C. de S. O desafio do conhecimento: pesquisa qualitativa em saúde. 2. ed. São Paulo: Hucitec, 1993.

NUNES, L.; FRANCO, L. F. M. Biblioterapia: formação e atuação do bibliotecário. Disponível em: <http://www.cab.ufsc.br/repositorio/trabalhoserebd2007/trabalho_14.pdf>. Acesso em: 30 set. 2011.

RIZO, L.; RANGÉ, B. Crianças desatentas, hiperativas e impulsivas: como lidar com essas crianças na escola? In: BRANDÃO et al. (Org.). Sobre o comportamento e cognição: a história e os avanços, a seleção por consequiências em ação. Santo André: Esetec, 2003. p. 422-432. Disponível em: <http: //www. lucianarizo.com.br/artigos/criancas_escola.pdf>. Acesso em: 9 abr. 2011.

STEFANI, M. S.; MASTROIANNI, E. de C. Q.; VIOTTO FILHO, I. A. T. As contribuições de um programa de atividades lúdicoscreativas na compreensão e superação do transtorno do déficit de atenção e hiperatividade (TDAH). 2009. Disponível em:

<http://prope.unesp.br/xxi_cic/27_36213410805.pdf>. Acesso em: 16 mar. 2011.

UNESCO. A criança descobrindo, interpretando e agindo sobre o mundo. Brasília, DF:

Fundação Maurício Sirotsy Sobrinho, 2005. Disponível em: <http://unesdoc.unesco.org/images/ 0013/001384/138429por.pdf>. Acesso em: 24 set. 2011.

VICTOR, M. TDAH ao longo da vida. In: Revista Brasileira de Psiquiatria, São Paulo, v. 31, n. 4, 2009. Disponível em: <http://www.scielo.br/scielo.php?script=sci_arttext\&pid= S151644462009000400025\&lang=pt>. Acesso em: 13 set. 2011. 